\title{
Current status of laparoscopic repeat liver resection for recurrent hepatocellular carcinoma
}

\author{
Daisuke Hokuto, Takeo Nomi, Takahiro Yoshikawa, Yasuko Matsuo, Naoki Kamitani, Masayuki Sho \\ Department of Surgery, Nara Medical University, Nara 634-8522, Japan.
}

Correspondence to: Dr. Takeo Nomi, Department of Surgery, Nara Medical University, 840 Shijo-cho, Kashihara-shi, Nara 6348522, Japan. E-mail: t.nomi45@gmail.com

\begin{abstract}
How to cite this article: Hokuto D, Nomi T, Yoshikawa T, Matsuo Y, Kamitani N, Sho M. Current status of laparoscopic repeat liver resection for recurrent hepatocellular carcinoma. Hepatoma Res 2020;6:81. http://dx.doi.org/10.20517/2394-5079.2020.78
\end{abstract}

Received: 8 Aug 2020 First Decision: 11 Sep 2020 Revised: 24 Sep 2020 Accepted: 16 Oct 2020 Published: 6 Nov 2020

Academic Editor: Ho-Seong Han Copy Editor: Cai-Hong Wang Production Editor: Jing Yu

\begin{abstract}
Repeat liver resection (RLR) is an effective treatment approach for recurrent hepatocellular carcinoma (HCC) and can provide acceptable long-term outcomes in select patients. Recent randomized controlled trials comparing RLR with radiofrequency ablation revealed that the latter approach was associated with a higher rate of early recurrence compared with RLR. With recent advances in laparoscopic liver resection (LLR), RLR has been increasingly performed using laparoscopy. Several propensity score-matched studies reported that laparoscopic RLR achieved lower blood loss and shorter hospital stays compared to open RLR. However, laparoscopic RLR requires more advanced techniques because of adhesions formed after the previous liver resection, changes in anatomical landmarks, and deformity of the remnant liver. The recently described difficulty classification of laparoscopic RLR is based on five factors including type of previous liver resection (open or laparoscopic), number of previous liver resections, surgical procedure used in previous liver resections, tumor location in previous liver resections, and difficulty score of LLR for recurrent HCC. We reviewed the available literature to summarize available evidence suggesting that laparoscopic RLR might be considered a more minimally invasive surgical treatment approach for recurrent HCC as long as the indication for laparoscopic RLR is carefully determined.
\end{abstract}

Keywords: Hepatocellular carcinoma, repeat liver resection, laparoscopic repeat liver resection

\section{INTRODUCTION}

Repeat liver resection (RLR) is an effective treatment approach for recurrent hepatocellular carcinoma (HCC) and can provide acceptable long-term outcomes for select patients ${ }^{[1-3]}$. However, RLR is considered

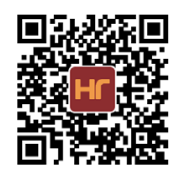


a difficult procedure due to adhesions associated with previous liver resection and changes in anatomical recognition. In fact, several studies have reported high morbidity rates after $\operatorname{RLR}^{[4-6]}$. With advances in laparoscopic liver resection (LLR), RLR has been increasingly performed laparoscopically ${ }^{[7]}$. LLR is a less invasive procedure that is associated with better short-term outcomes compared with open liver resection $(\mathrm{OLR})^{[8,9]}$. Similarly, the superiority of laparoscopic RLR over open RLR in short-term outcomes has been reported ${ }^{[10-12]}$. However, none of the studies were randomized controlled trials and laparoscopic RLR might be performed in select patients. Laparoscopic RLR was discussed at the first European Guidelines Meeting on Laparoscopic Liver Surgery (Southampton 2017) and considered an appropriate option ${ }^{[13]}$. However, most laparoscopic liver surgeons suggest that repeat liver resection significantly increases the difficulty of $L_{L R}{ }^{[14]}$. Currently, the indications for laparoscopic RLR vary between centers. Considered a difficult procedure, RLR poses a range of challenges depending on the location of recurrent tumor and previous liver resections. A recent report has introduced a difficulty classification for laparoscopic $\operatorname{RLR}^{[15]}$. Specifically, the level of difficulty was determined on the basis of the type of previous liver resection (open or laparoscopic), number of previous liver resections, surgical procedure and tumor location in previous liver resections, and difficulty score of LLR for recurrent HCC ${ }^{[16]}$. RLR after LLR has been increasing in parallel with the increasing number of LLR for HCC. In colorectal surgery, the laparoscopic approach has been reported to reduce adhesion formation ${ }^{[17]}$. Similarly, RLR after LLR is associated with less adhesion formation compared with RLR performed after OLR. Therefore, RLR in the era of LLR has distanced characteristics. Conversely, percutaneous radiofrequency ablation (RFA), a technique developed in the last two decades ${ }^{[18,19]}$, has been demonstrated to be useful in small $\mathrm{HCCs}^{[20]}$. In general, patients who previously undergo hepatectomy for HCC are examined regularly by imaging studies, which facilitate the frequent detection of small-diameter recurrent HCCs. Within this framework, the role of liver resection for recurrent HCC might be changing. In this review, we describe the current status of laparoscopic RLR for HCC in the era of LLR and RFA.

\section{SIGNIFICANCE OF REPEAT LIVER RESECTION FOR RECURRENT HEPATOCELLULAR CARCINOMA}

Relatively good survival outcomes of RLR for HCC have been reported since the $1990 \mathrm{~s}^{[21-24]}$. These earlier studies reported that 5-year survival rate after RLR was around 50\%, which was comparable to the prognosis of primary liver resection and was better than the prognosis of transarterial chemoembolization ${ }^{[25,26]}$. However, RLR was performed in select patients with relatively better liver function and tumor factors compared to those undergoing transarterial chemoembolization. Moreover, disease-free survival rates were significantly lower with RLR compared to initial liver resection ${ }^{[2,3]}$. Studies investigating prognostic factors after RLR for HCC reported that portal vein invasion at the time of first liver resection, portal vein invasion in RLR, multiple HCCs at the time of first liver resection, and disease-free interval of less than one year were independent prognostic factors after $\operatorname{RLR}^{[1,3,27]}$. The 5 -year survival rate was $86.0 \%$ in patients without prognostic factors ${ }^{[1]}$. These results provide clear evidence that RLR for recurrent HCC is a useful treatment option for select patients.

In the last decade, several studies investigating long-term outcomes in patients undergoing three or more RLRs reported that the 5-year survival and disease-free survival rates after the third RLR were $40.0 \%-68.2 \%$ and $12.8 \%-33.8 \%$, respectively ${ }^{[6,28,29]}$. These results were comparable to those observed after the second RLR. Regarding short-term outcomes, Mise et al. ${ }^{[6]}$ reported significantly longer surgical duration and higher postoperative morbidity with three or more RLRs, whereas Yamashita et al ${ }^{[28]}$ reported no significant differences. These results indicated that three or more RLRs might be considered an acceptable treatment approach in patients whose liver function and tumor factors were within surgical indications. 


\section{ADVANCES IN LAPAROSCOPIC REPEAT LIVER RESECTION}

Progress in surgical procedures and devices has enabled the expansion of surgical indications for $\operatorname{LLR}^{[30-32]}$. However, laparoscopic RLR demands a more advanced technique due to adhesion formation following prior liver resection, changes in anatomical landmarks, and deformity of the remnant liver. In 2009, Belli et al. ${ }^{[33]}$ reported 12 patients who underwent laparoscopic RLR for recurrent HCC. The authors concluded that laparoscopic RLR was feasible and that the degree of adhesion was mild in patients undergoing LLR as initial liver resection. In 2011, Hu et al. ${ }^{[34]}$ reported six patients who underwent laparoscopic RLR for recurrent HCC. No intra- or postoperative complications were observed; however, the authors noted that the patients were carefully selected. Another report in 2011 was a tri-institutional analysis of 76 patients undergoing laparoscopic $\operatorname{RLR}^{[35]}$. The study cohort comprised 63, 3, and 10 patients with metastatic liver tumors, HCC and benign tumors, respectively. Seven patients (9.2\%) were converted to open surgery, and there were no perioperative deaths. The patients who underwent OLR as initial liver resection experienced higher intraoperative blood loss compared to those who underwent LLR. In 2016, a review by Goh et al. ${ }^{[36]}$, which included 103 patients who underwent laparoscopic RLR for recurrent HCC, reported that only 2 patients $(1.9 \%)$ were converted to open surgery. These retrospective analyses have provided evidence for the feasibility and safety of LLR in select patients.

In 2018, Noda et al. ${ }^{[37]}$, and Ome et al. ${ }^{[38]}$, reported their findings on the comparison between laparoscopic RLR and open RLR in their institutions indicating that blood loss was less and hospital stay shorter with laparoscopic RLR; there were no differences in operative duration and postoperative complications. Thereafter, similar results have been reported from several single centers ${ }^{[7,12,39]}$. In 2019 , a multicenter propensity score-matched study compared laparoscopic and open RLR for colorectal liver metastasis ${ }^{[40]}$. After matching, 105 pairs were extracted from the initial cohort of 271 patients who underwent laparoscopic RLR and 154 patients who underwent open RLR. Laparoscopic RLR was associated with a significantly shorter operative duration (200 $\mathrm{min} v s .256 \mathrm{~min}$ ), less intraoperative blood loss (200 $\mathrm{mL} v s$. $300 \mathrm{~mL}$ ), and shorter postoperative hospital stay (5 days vs. 6 days), whereas postoperative morbidity and mortality rates were similar between the groups. Similar results of laparoscopic RLR for HCC were reported in another multicenter propensity score based study ${ }^{[11]}$. Table 1 summarizes the comparison between laparoscopic RLR and open RLR of these reports.

Although no randomized controlled trials to date have compared laparoscopic RLR and open RLR, evidence from previous studies indicate that laparoscopic RLR is feasible and safe as long as the indications are within the capabilities of institutions and surgeons.

\section{DIFFICULTY CLASSIFICATION OF LAPAROSCOPIC REPEAT LIVER RESECTION}

Several factors affect the level of difficulty in laparoscopic LLR. Previous OLR was reported to increase difficulty in laparoscopic $\operatorname{RLR}^{[33,35]}$. In 2014, Ban et al. ${ }^{[16]}$ described the first difficulty scoring system for LLR. The difficulty score was based on tumor location, extent of liver resection, tumor size, tumor proximity to major vessels and liver function. The difficulty of LLR was classified into low, intermediate and high levels. This score can be effortlessly utilized for risk assessment in patients undergoing laparoscopic RLR. Recently, Kinoshita et al. ${ }^{[15]}$ reported on difficulty classification of laparoscopic RLR. They reviewed 60 cases of laparoscopic RLR in their institution and analyzed the factors accounting for prolonged operative duration or severe adhesion. As a result, an intermediate or high LLR difficulty score, two or more previous liver resections, a history of previous major liver resection, and tumor location near the resected surface of previous liver resection were identified. These five factors were reported to be correlated with operative duration in laparoscopic RLR. The authors then classified the patients undergoing RLR into low-risk (score, 0-1), intermediate-risk (score, 2-3), and high-risk (score, 4-5) categories and found that the risk was significantly correlated with operative duration ${ }^{[15]}$. 
Table 1. Outcome of treatment after recurrent hepatocellular carcinoma

\begin{tabular}{|c|c|c|c|}
\hline & $\begin{array}{l}\text { Laparoscopic repeat liver } \\
\text { resection (laparoscopic RLR) }\end{array}$ & $\begin{array}{c}\text { Open repeat liver resection } \\
\text { (open RLR) }\end{array}$ & $P$ value \\
\hline \multicolumn{4}{|l|}{ Morise et al. ${ }^{[11]}$ (2020) } \\
\hline Blood loss (mL) & 268 & 497 & 0.001 \\
\hline Duration of operation (min) & 272 & 232 & 0.007 \\
\hline 90-day morbidity, beyond Clavien-dindo II (\%) & 15.1 & 13.0 & 0.611 \\
\hline 90-day Mortality (\%) & 0.42 & 0.84 & 0.623 \\
\hline Postoperative hospital stay (days) & 10.4 & 9.6 & 0.327 \\
\hline \multicolumn{4}{|l|}{ van der Poel et al. ${ }^{[40]}$ (2019) } \\
\hline Blood loss $(\mathrm{mL})$ & $200(50-450)$ & $300(100-600)$ & 0.077 \\
\hline Duration of operation (min) & $200(123-273)$ & $256(199-320)$ & $<0.001$ \\
\hline 90-day morbidity, beyond Clavien-dindo II (\%) & 5.7 & 5.7 & 0.319 \\
\hline 90-day Mortality (\%) & 1.9 & 0 & 0.5 \\
\hline Postoperative hospital stay (days) & $5(3-8)$ & $6(5-8)$ & 0.028 \\
\hline \multicolumn{4}{|l|}{ Onoe et al. ${ }^{[39]}(2020)$} \\
\hline Blood loss $(\mathrm{mL})$ & $100(0-1050)$ & $435(30-1920)$ & 0.001 \\
\hline Duration of operation (min) & $276(125-589)$ & $292(96-972)$ & 0.861 \\
\hline 90-day morbidity, beyond Clavien-dindo III (\%) & 6.75 & 14.3 & 0.297 \\
\hline 90-day Mortality (\%) & 0 & 0 & 1 \\
\hline Postoperative hospital stay (days) & $10(4-50)$ & $14.5(10-76)$ & 0.002 \\
\hline \multicolumn{4}{|l|}{ Goh et al. ${ }^{[12]}(2019)$} \\
\hline Blood loss $(\mathrm{mL})$ & $200(100-425)$ & $250(125-475)$ & 0.345 \\
\hline Duration of operation (min) & $315(181-395)$ & $125(99-184)$ & $<0.001$ \\
\hline 30-day morbidity, beyond Clavien-dindo III (\%) & 0 & 5 & 0.48 \\
\hline 30-day Mortality (\%) & 0 & 10 & 0.56 \\
\hline Postoperative hospital stay (days) & $4(3-5)$ & $7.5(6-10)$ & 0.001 \\
\hline \multicolumn{4}{|l|}{ Ome et al. ${ }^{[38]}(2018)$} \\
\hline Blood loss $(\mathrm{mL})$ & $30(0-1012)$ & $652(20-12046)$ & $<0.001$ \\
\hline Duration of operation (min) & $217(43-356)$ & $222(84-923)$ & 0.56 \\
\hline 30-day morbidity, beyond Clavien-dindo III (\%) & 6.1 & 10.8 & 0.393 \\
\hline 30-day Mortality (\%) & 3 & 0 & 0.471 \\
\hline Postoperative hospital stay (days) & $6.5(3-47)$ & $9.0(5-78)$ & $<0.001$ \\
\hline \multicolumn{4}{|l|}{ Noda et al. ${ }^{[37]}(2018)$} \\
\hline Blood loss $(\mathrm{mL})$ & 159 & 502 & 0.004 \\
\hline Duration of operation (min) & 225 & 237 & 0.601 \\
\hline 30-day morbidity, beyond Clavien-dindo III (\%) & 0 & 14.5 & 0.009 \\
\hline 30-day Mortality (\%) & 0 & 0 & 1 \\
\hline Postoperative hospital stay (days) & 14.2 & 19.2 & 0.028 \\
\hline
\end{tabular}

\section{LONG-TERM OUTCOMES AFTER LAPAROSCOPIC REPEAT LIVER RESECTION FOR RECURRENT HEPATOCELLULAR CARCINOMA}

A global systematic review and meta-analysis in 2013 reported that the long-term outcomes were comparable between LLR and OLR for initial $\mathrm{HCC}^{[41]}$. Subsequently, propensity score-matched studies comparing LLR and OLR for initial HCC revealed that overall survival (OS) and recurrence-free survival (RFS) were not different between LLR and OLR, while short-term outcomes were significantly better with $\operatorname{LLR}^{[42-44]}$. Similar results were obtained in a study limited to patients undergoing major hepatectomy ${ }^{[45]}$. However, no randomized controlled trials have compared LLR and OLR for initial HCC. LLR might be performed in select patients. Moreover, Stiles et al. ${ }^{[46]}$ reported that unplanned conversion to OLR from LLR for HCC was associated with inferior OS compared to non-converted cases. Therefore, the long-term prognosis of LLR might be comparable to OLR as long as the indication for LLR is carefully evaluated. Regarding RLR, few studies have compared long-term survival outcomes between laparoscopic RLR and open RLR. A recent multicenter, propensity score-based study by Morise et al. ${ }^{[11]}$, which included 42 surgery centers around the world, reported comparable median survival times between laparoscopic RLR and open RLR (12.55 years $v s .8 .94$ years; $P=0.086$ ), although intraoperative blood loss was significantly 
greater with open RLR (268 mL vs. $497 \mathrm{~mL} ; P=0.001)$ and operative duration was significantly longer with laparoscopic LLR (272 min vs. $232 \mathrm{~min} ; P=0.007$ ). These findings suggest acceptable long-term outcomes with laparoscopic RLR for recurrent HCC.

\section{LAPAROSCOPIC REPEAT LIVER RESECTION AND RADIOFREQUENCY ABLATION FOR RECURRENT HEPATOCELLULAR CARCINOMA}

Percutaneous RFA, a technique developed in the last two decades has been reported to be an effective and safe treatment for small HCCs ${ }^{[18-20]}$. Nowadays, RFA is widely used as non-surgical treatment for HCCs because the therapeutic effect was reported to be more effective than microwave coagulation therapy or percutaneous ethanol injection therapy ${ }^{[4,48]}$. In general, recurrent HCCs are detected at a small diameter because of routine screening after initial liver resection. Therefore, RFA for recurrent HCCs could be an effective treatment.

However, a very recent randomized controlled trial comparing RLR with RFA for recurrent HCC revealed that RFA was associated with a higher rate of early recurrence compared with RLR $(40.3 \%$ vs. $23.3 \%, P=$ $0.04)^{[49]}$. On the other hand, the trial results indicated that RLR had a higher complication rate than RFA (22.4\% vs. $7.3 \%, P=0.001)$. These findings highlight that RLR remains an important treatment approach for recurrent HCC even in the era of RFA. As mentioned previously, laparoscopic RLR can be performed safely, with less blood loss and shorter postoperative hospital stay compared to open RLR in select cases. Therefore, laparoscopic RLR for recurrent HCC might be considered a standard treatment with reduced surgical invasiveness as long as the indication for RLR is carefully considered.

\section{CONCLUSION}

RLR for recurrent HCC remains an important treatment strategy even in the era of RFA. Laparoscopic RLR could be considered a more minimally invasive surgical treatment than open RLR for patients with recurrent HCC.

\section{DECLARATIONS}

\section{Authors' contributions}

Wrote this article: Hokuto D

Supervised this article: Nomi T, Sho M

Treated the patients included in this article: Yoshikawa T, Matsuo Y, Kamitani N

\section{Availability of data and materials}

Not applicable.

\section{Financial support and sponsorship}

None.

\section{Conflicts of interest}

All authors declared that there are no conflicts of interest.

\section{Ethical approval and consent to participate}

Not applicable.

\section{Consent for publication}

Not applicable. 


\section{Copyright}

(c) The Author(s) 2020.

\section{REFERENCES}

1. Minagawa M, Makuuchi M, Takayama T, Kokudo N. Selection criteria for repeat hepatectomy in patients with recurrent hepatocellular carcinoma. Ann Surg 2003;238:703-10.

2. Nakajima Y, Ko S, Kanamura T, et al. Repeat liver resection for hepatocellular carcinoma11No competing interests declared. Journal of the American College of Surgeons 2001;192:339-44.

3. Shimada M, Takenaka K, Taguchi K, et al. Prognostic factors after repeat hepatectomy for recurrent hepatocellular carcinoma. Ann Surg 1998;227:80-5.

4. Sadamori H, Yagi T, Shinoura S, et al. Risk factors for major morbidity after liver resection for hepatocellular carcinoma. $\mathrm{Br} J$ Surg 2013;100:122-9.

5. Yoshioka R, Saiura A, Koga R, Seki M, Kishi Y, Yamamoto J. Predictive factors for bile leakage after hepatectomy: analysis of 505 consecutive patients. World J Surg 2011;35:1898-903.

6. Mise Y, Hasegawa K, Shindoh J, et al. The feasibility of third or more repeat hepatectomy for recurrent hepatocellular carcinoma. Ann Surg 2015;262:347-57.

7. Wakabayashi T, Felli E, Memeo R, et al. Short-term outcomes of laparoscopic repeat liver resection after open liver resection: a systematic review. Surg Endosc 2019;33:2083-92.

8. Fretland ÅA, Dagenborg VJ, Bjørnelv GMW, et al. Laparoscopic versus open resection for colorectal liver metastases: the OSLOCOMET randomized controlled trial. Ann Surg 2018;267:199-207.

9. Ciria R, Cherqui D, Geller DA, Briceno J, Wakabayashi G. Comparative short-term benefits of laparoscopic liver resection: 9000 cases and climbing. Ann Surg 2016;263:761-77.

10. Liang Y, Lin C, Zhang B, et al. Perioperative outcomes comparing laparoscopic with open repeat liver resection for post-hepatectomy recurrent liver cancer: a systematic review and meta-analysis. Int J Surg 2020;79:17-28.

11. Morise Z, Aldrighetti L, Belli G, et al; ILLS-Tokyo collaborator group. Laparoscopic repeat liver resection for hepatocellular carcinoma: a multicentre propensity score-based study. Br J Surg 2020;107:889-95.

12. Goh BKP, Syn N, Teo JY, et al. Perioperative outcomes of laparoscopic repeat liver resection for recurrent HCC: comparison with open repeat liver resection for recurrent HCC and laparoscopic resection for primary HCC. World J Surg2019;43:878-85.

13. Abu Hilal M, Aldrighetti L, Dagher I, et al. The southampton consensus guidelines for laparoscopic liver surgery: from indication to implementation. Ann Surg 2018;268:11-8.

14. Halls MC, Cherqui D, Taylor MA, Primrose JN, Abu Hilal M; Collaborators of The Difficulty of Laparoscopic Liver Surgery Survey. Are the current difficulty scores for laparoscopic liver surgery telling the whole story? An international survey and recommendations for the future. HPB (Oxford) 2018;20:231-6.

15. Kinoshita M, Kanazawa A, Kodai S, et al. Difficulty classifications of laparoscopic repeated liver resection in patients with recurrent hepatocellular carcinoma. Asian J Endosc Surg 2020;13:366-74.

16. Ban D, Tanabe M, Ito H, et al. A novel difficulty scoring system for laparoscopic liver resection. J Hepatobiliary Pancreat Sci 2014;21:745-53.

17. Dowson HM, Bong JJ, Lovell DP, Worthington TR, Karanjia ND, Rockall TA. Reduced adhesion formation following laparoscopic versus open colorectal surgery. Br J Surg 2008;95:909-14.

18. Tiong L, Maddern GJ. Systematic review and meta-analysis of survival and disease recurrence after radiofrequency ablation for hepatocellular carcinoma. Br J Surg 2011;98:1210-24.

19. Lau WY, Lai EC. The current role of radiofrequency ablation in the management of hepatocellular carcinoma: a systematic review. Ann Surg 2009;249:20-5.

20. Kang TW, Kim JM, Rhim H, et al. Small hepatocellular carcinoma: radiofrequency ablation versus nonanatomic resection--propensity score analyses of long-term outcomes. Radiology 2015;275:908-19.

21. Matsuda Y, Ito T, Oguchi Y, Nakajima K, Izukura T. Rationale of surgical management for recurrent hepatocellular carcinoma. Ann Surg 1993;217:28-34.

22. Shimada M, Matsumata T, Taketomi A, Yamamoto K, Itasaka H, Sugimachi K. Repeat hepatectomy for recurrent hepatocellular carcinoma. Surgery 1994115:703-6.

23. Suenaga M, Sugiura H, Kokuba Y, Uehara S, Kurumiya T. Repeated hepatic resection for recurrent hepatocellular carcinoma in eighteen cases. Surgery 1994;115:452-7.

24. Hu RH, Lee PH, Yu SC, et al. Surgical resection for recurrent hepatocellular carcinoma: prognosis and analysis of risk factors. Surgery 1996;120:23-9.

25. Takayasu K, Wakao F, Moriyama N, et al. Postresection recurrence of hepatocellular carcinoma treated by arterial embolization: analysis of prognostic factors. Hepatology 1992;16:906-11.

26. Okazaki M, Yamasaki S, Ono H, Higashihara H, et al. Chemoembolotherapy for recurrent hepatocellular carcinoma in the residual liver after hepatectomy. Hepatogastroenterology 1993;40:320-3.

27. Itamoto T, Nakahara H, Amano H, et al. Repeat hepatectomy for recurrent hepatocellular carcinoma. Surgery 2007;141:589-97.

28. Yamashita Y, Shirabe K, Tsuijita E, et al. Third or more repeat hepatectomy for recurrent hepatocellular carcinoma. Surgery 

2013; 154:1038-45.

29. Wu CC, Cheng SB, Yeh DC, Wang J, P'eng FK. Second and third hepatectomies for recurrent hepatocellular carcinoma are justified. $B r J$ Surg 2009;96:1049-57.

30. Kaneko H, Takagi S, Shiba T. Laparoscopic partial hepatectomy and left lateral segmentectomy: Technique and results of a clinical series. Surgery 1996;120:468-75.

31. Nitta H, Sasaki A, Fujita T, et al. Laparoscopy-assisted major liver resections employing a hanging technique: the original procedure. Ann Surg 2010;251:450-3.

32. Buell JF, Thomas MT, Rudich S, et al. Experience with more than 500 minimally invasive hepatic procedures. Ann Surg 2008;248:475-86.

33. Belli G, Cioffi L, Fantini C, et al. Laparoscopic redo surgery for recurrent hepatocellular carcinoma in cirrhotic patients: feasibility, safety, and results. Surg Endosc 2009;23:1807-11.

34. Hu M, Zhao G, Xu D, Liu R. Laparoscopic repeat resection of recurrent hepatocellular carcinoma. World J Surg 2011;35:648-55.

35. Shafaee Z, Kazaryan AM, Marvin MR, et al. Is laparoscopic repeat hepatectomy feasible? A tri-institutional analysis. J Am Coll Surg 2011;212:171-9.

36. Goh BK, Teo JY, Chan CY, Lee SY, Cheow PC, Chung AY. Review of 103 Cases of Laparoscopic Repeat Liver Resection for Recurrent Hepatocellular Carcinoma. J Laparoendosc Adv Surg Tech A 2016;26:876-81.

37. Noda T, Eguchi H, Wada H, et al. Short-term surgical outcomes of minimally invasive repeat hepatectomy for recurrent liver cancer. Surg Endosc 2018;32:46-52.

38. Ome Y, Hashida K, Yokota M, et al. The feasibility and efficacy of pure laparoscopic repeat hepatectomy. Surg Endosc 2018;32:3474-9.

39. Onoe T, Yamaguchi M, Irei T, et al. Feasibility and efficacy of repeat laparoscopic liver resection for recurrent hepatocellular carcinoma. Surg Endosc 2020;34:4574-81.

40. van der Poel MJ, Barkhatov L, Fuks D, et al. Multicentre propensity score-matched study of laparoscopic versus open repeat liver resection for colorectal liver metastases. Br J Surg 2019;106:783-9.

41. Yin Z, Fan X, Ye H, Yin D, Wang J. Short- and long-term outcomes after laparoscopic and open hepatectomy for hepatocellular carcinoma: a global systematic review and meta-analysis. Ann Surg Oncol 2013;20:1203-15.

42. Lee JJ, Conneely JB, Smoot RL, et al. Laparoscopic versus open liver resection for hepatocellular carcinoma at a North-American Centre: a 2-to-1 matched pair analysis. HPB (Oxford) 2015;17:304-10.

43. Han HS, Shehta A, Ahn S, Yoon YS, Cho JY, Choi Y. Laparoscopic versus open liver resection for hepatocellular carcinoma: Casematched study with propensity score matching. J Hepatol 2015;63:643-50.

44. Sposito C, Battiston C, Facciorusso A, et al. Propensity score analysis of outcomes following laparoscopic or open liver resection for hepatocellular carcinoma. Br J Surg 2016;103:871-80.

45. Komatsu S, Brustia R, Goumard C, Perdigao F, Soubrane O, Scatton O. Laparoscopic versus open major hepatectomy for hepatocellular carcinoma: a matched pair analysis. Surg Endosc 2016;30:1965-74.

46. Stiles ZE, Glazer ES, Deneve JL, Shibata D, Behrman SW, Dickson PV. Long-Term Implications of Unplanned Conversion During Laparoscopic Liver Resection for Hepatocellular Carcinoma. Ann Surg Oncol 2019;26:282-9.

47. Ohmoto K, Yoshioka N, Tomiyama Y, et al. Comparison of therapeutic effects between radiofrequency ablation and percutaneous microwave coagulation therapy for small hepatocellular carcinomas. J Gastroenterol Hepatol 2009;24:223-7.

48. Seki T, Wakabayashi M, Nakagawa T, et al. Percutaneous microwave coagulation therapy for patients with small hepatocellular carcinoma: comparison with percutaneous ethanol injection therapy. Cancer 1999;85:1694-702.

49. Xia Y, Li J, Liu G, et al. Long-term Effects of Repeat Hepatectomy vs Percutaneous Radiofrequency Ablation Among Patients With Recurrent Hepatocellular Carcinoma: A Randomized Clinical Trial. JAMA Oncol 2020;6:255-63. 